\title{
ENVIRONMENTAL IMPACT ASSESSMENT - NECESSITY, PRINCIPLES AND SPECIFICITIES
}

\author{
M. Sabeva* \\ Department „Economics of Natural Resources”, University of National and World Economy (UNWE), \\ Sofia, Bulgaria
}

\begin{abstract}
One of the most important procedures related to nature conservation and achieving the goals of sustainable development is the assessment of the environmental impact of investment proposals (EIA). This procedure is an essential tool for preventive control.

The purpose of EIA is to identify, describe and assess the various direct and indirect impacts of investment proposals on humanity and the components of the environment, before implementing the relevant investment proposals.

There are eight leading principles that govern the entire EIA process, namely participation, transparency, security, accountability, credibility, cost efficiency, flexibility and practicality.

In the EIA procedure the following features are observed:

1) The EIA process is informative, not regulatory. The main challenge is how the recommendations of the evaluation and compliance with the EPA (Environmental Protection Act) to become an effective tool for environmental management.

2) Experience shows that almost no EIA is performed prior to the approval of any project and the most of EIA Reports actually intend to justify the project and to answer the criticisms of the stakeholders.

According to the World Economic Forum, the most serious environmental threats caused by man are pollution, mismanagement of land and water, overexploitation of species unprecedented geophysical destruction and mismanagement of urbanization. EIA, as one of the key instruments for preventive control, takes an important role in the development of investment proposals and in achievement of the objectives of sustainable development, reducing the negative impacts on the environment and improving its quality.
\end{abstract}

Key words: Environmental Impact Assessment (EIA); nature conservation; sustainable development; preventive control

Jel Codes: Q01; Q50; Q56; Q57; Q59

\section{INTRODUCTION}

Any investment proposal, project, plan or program, during its implementation, affects environmental components (air, atmosphere, water, soil, subsoil, landscape, natural sites, mineral diversity, biodiversity and its elements). In order to keep the ecological balance, to protect nature and to avoid lowering the quality of life, while developing infrastructure and economy, some mandatory requirements, procedures and standards have been introduced,

\footnotetext{
*Correspondence to: Monika Sabeva Department „Economics of Natural Resources”, University of National and World Economy (UNWE), 1700, Sofia, Bulgaria, Student town, ,8th December” Blvd.
}

regarding the environment by assessing the impact on it as a result of various economic, social and other activities. Environmental assessment generally aims to integrate the predictions regarding the environment in the development process and achieving sustainable development. The proper execution of procedures for protecting the environment and at the same time, satisfaction of the public interest, need to combine the efforts and collaboration of the competent authorities (state and municipal), governmental and non-governmental organizations, experts on the species assessments and a full public interest and participation.

Within the EU [1], but worldwide as well, many different methods and approaches for 
assessing the environmental impact in the implementation of relevant strategic and management decisions at various levels are applied. One of the most important procedures, related to nature conservation and achieving the goals of sustainable development, is the assessment of environmental impacts of development proposals (EIA). This procedure is an essential tool for preventive control. Its main objective is to achieve sustainable development and evaluation of potential impacts on the environment, before implementing the relevant investment proposals. Based on the results, some measures, alternatives and solutions for implementing and enforcing the investment proposals are provided in order to minimize the adverse impacts on the environment and to contribute for improving its quality. Thus support the final decision for approving or disapproving the relevant strategic and planning documents (investment proposals).

\section{The Environmental Impact Assessment} (EIA) [2] procedure is a part of the preventive measures that should be taken in order to reduce and prevent environmental pollution. It is performed for assessing the impact of an investment proposal on environment and to evaluate the admissibility of this investment proposal by assessing the nature of its technology, activities or constructions and their impact on environment. The different alternatives for realization of an investment proposal are evaluated by the selected technology and by location. There also should be considered a zero alternative, in which the project will not be realized.

The EIA [3] is carried out for investment proposals for construction, activities and technologies in Applications № 1 and 2 of the EPA (Environmental Protection Act) or their modifications or extensions in which implementation it is possible significant environmental impacts to occur.

In its essence EIA [4] [5] is a legal instrument, established to implement preventive control in managing the environment by minimizing the adverse effects of human activities. EIA describes and assesses in an appropriate manner the direct and indirect impacts of investment proposals on man, environment and landscape in each case. It includes decisions, related mainly to the technological characteristics of the investment proposal, concerning more limiting than preventing the environmental impacts. The EIA procedure should apply to those public and private investment proposals, which are expected to have a significant impact on environment.

The purpose of EIA [4] [5] is to identify, describe and assess the various direct and indirect impacts of the investment proposals on man and on the components of environment and the EIA should provide decision-makers a sufficient information about it. There should be a reconciliation of expectations for sustainable development of the environment with the principles of environmental protection, integrated in various sectoral politics.

Objects of EIA [4] [5], according to the EPA, are the investment proposals for construction, activities and technologies that have a direct national or transboundary affects, which combine expectations for sustainable development in accordance with the principles of environmental protection, integrated in sectoral politics transport, energy, construction, agriculture, tourism, industry, education and others.

Subjects or authorities of EIA [4] decisionmaking are the Minister of Environment and Water (MoEW) and the Directors of Regional Inspectorates of Environment and Water (RIEW)and specialized agencies and experts authorized by them.

The EIA procedure in Bulgaria [6] [7] was introduced in 1991 with the adoption of the EPA - the first act concerning the environment of the transitional period. The procedure complies with the Directive 85/337/EU and introduces preventive action as a fundamental principle of environmental management. In 1992 was adopted the first EIA Regulation № 1, which sets the details and requirements for the procedure set out in the Act. As a result of practical experience, it becomes 
necessary a new Regulation on EIA to be prepared and be entred into force in 1995 .

Following the practical development of the EIA process in Bulgaria and in the European Union, EPA, in the EIA part, was changed several times, thus improving the rules and requirements of EIA. In 1998 the 1995 Regulation was repealed and a new regulation №4 was adopted for assessing the impact on environment. This was necessary in order to meet the requirements for compliance of Bulgarian with the EU legislation and fully engaging the EU practice. A significant portion of Directive 97/11/EU for amending the EIA Directive 85/337/EEC is reflected. The requirements to the scope and content of EIA reports for plans and programs, projects and operating facilities are precised, the process sequences for different projects and objects and the place of EIA in the process of approving and enabling investment proposals are regulated in details; the beginning of statutory control for implementation of terms, issued by the competent EIA authorities was set. The EIA procedure for projects with transboundary impact, in accordance with the ratified by Bulgaria in 1995 Convention on Environmental Impact Assessment in a Transboundary Context, is also regulated.

Public participation becomes an obligatory and essential part of the EIA procedure in Bulgaria.

The Legislation clearly regulates the procedure for judicial review of decisions, taken by the EIA competent authorities MoEW or RIEW.

In 2003 a new Regulation on conditions and procedures for assessing the environmental impact is adopted. It, after amending and supplementing in the period 2006-2011, is currently operational.

EIA [8] is considered as a tool for project management and collecting and analysing information on the environmental impacts that may occur as a result of realization of an investment proposal. In this sense, it is used for:

1) Identification of potential environmental impacts;
2) Studying the significant environmental impacts;

3) Assessing the probability these impacts to be mitigated;

4) Recommending preventive and corrective measures to reduce the negative impacts;

5) Informing decision-makers and stakeholders on the environmental consequences;

6) Giving opinion (council) whether the development of the relevant investment proposal should continue.

What necessitates this assessment positive and negative features of the method:

1) When EIA is recommended [4] - If the project is under the orders of Annex I of EPA, EIA is mandatory. If it is under the orders of Annex II of EPA, the need for EIA is assessed by elements for each case based on specific criteria, and if not covered by the Applications but concerns elements of the National Ecological Network (NATURA 2000), the need for EIA is also assessed for each case under the relevant criteria.

2) Restrictions and characteristics of EIA:

$>$ EIA [9] is a process by which the expected environmental impacts of investment proposals or projects are assessed. If possible effects are unacceptable, it is recommended some measures to be taken in order to reduce or avoid those impacts.

Although EIA are now widely implemented, there are a number of important questions regarding the process and results. [10] The EIA process is informative, not regulatory, such as laws on pollution. There is also a confusion, because of the fact that often, when the conclusion is that there is a high probability of occurrence of adverse environmental impacts, after all it is decided that the investment proposal should be implemented.

$>$ The main challenge here [11] is how the recommendations of the evaluation and the provisions of the EPA to become an effective tool for environmental management. This is crucial because in many cases the implementation of 
legislation tolerate failure in the implementation stage.

Regarding the experience [11], especially in the terms of infrastructure projects, shows that EIA is almost never carried out, prior to approval of any project. The principle of integration the programs for environmental protection in the implementation of these projects, is often violated. The government routinely approves proposals before the EIA implementation. So most EIA Reports actually intend to justify the project and to answer the criticism of stakeholders, NGOs and the public. Even if the necessary assessments were carried out, the detailed procedure provided in the Act/Guidelines is usually disregarded, especially the consultations. Insufficient consultations usually raise concerns or unrealistic expectations, which often occur in unjustified fears that the project could lead to adverse impacts or hopes that the projects can bring any benefits.

There are eight guiding principles that govern the entire process of EIA [4], namely:

1) Participation - All interested parties should have full and timely access to the process;

2) Transparency - All evaluation decisions and the reasons (conditions) for making the decisions, must be open and accessible;

3) Security - The evaluation process and the duration of the assessment should be agreed in advance and to be observed by all participants;

4) Accountability - Decision-makers have the responsibility to take the appropriate actions and decisions in the assessment process;

5) Credibility - The evaluation should be professionally and objectively implemented;

6) Cost Effectiveness - The evaluation process and its results should guarantee the environmental protection at the lowest cost for society;

7) Flexibility - The evaluation process should be able to adapt and deal effectively with any proposal and newly occurred situation, regarding the evaluation;

8) Practicability - Information and results, provided in the evaluation process, should be easy to use in decisionmaking and planning.

\section{Stages of EIA[8]:}

The activities, related to the conduct of the procedure, include the issues of preparation of investment proposals to implementation of the decisions, contained in the EIA report. Evaluation of environmental impact is carried out in the following sequence:

1) First stage - Project screening - Not all development projects require EIA. Screening of the project will help to identify those projects that actually need to be evaluated. The verification is performed according to specific criteria;

2) Second stage - Scope of the assessment - This process helps determining the coverage or scope of the EIA by specially developed methods;

3) Third stage - Collecting basic data Briefly explanation of the concept of collecting baseline data and the purpose of this procedure;

4) Fourth stage - Identification of environmental impact - Describing the different types of environmental impacts of the projects and taking into account both positive and negative impacts;

5) Fifth stage - Comparing the impacts of selected alternatives and determining their importance Defining and describing the reasons for the potential impact, the degree of uncertainty regarding the impact and making predictions and comparisons of the alternatives;

6) Sixth stage - Mitigating measures Brief description of the concept and purpose, the types and characteristics of measures for mitigating the impact;

7) Seventh stage - Public consultation and participation - Public participation is a necessary and important component of the EIA. At this stage there should be given an answer to the questions: "Who are the stakeholders?", "How they should be involved in the process?" and 
"What are the benefits/damages to them?"

8) Eighth stage $\quad$ Environmental Monitoring - Environmental monitoring is one of the most important aspects of the EIA. At this stage, the principles, types and institutional aspects are defined and the corresponding explanations for monitoring the environment are given;

9) Ninth stage - Environmental audit Here the various types of environmental audits are described and it is specified when and how they should be included in the EIA process.

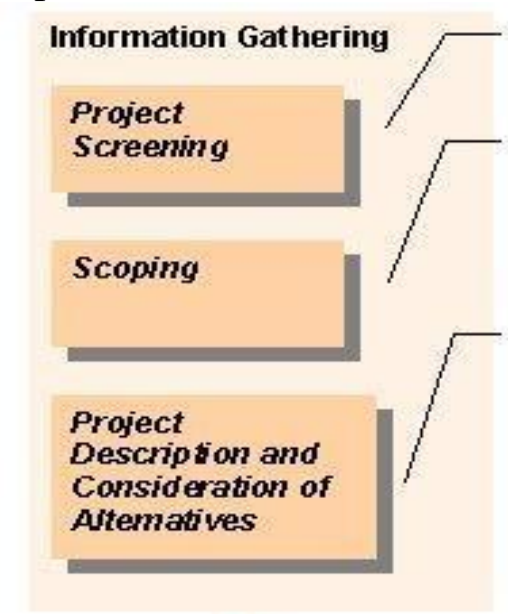

Determines necessity for ElA.A. requirement

- Identifies potentially impact

- Provides project

alternatives

- Provide basis for developing TOR

Describe all possible project alternatives, such as

- Location

- Scale

- Process

- Layout

- Operating conditions

- Etc

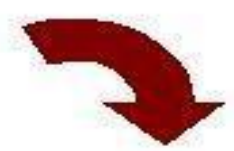

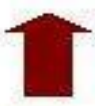

Stakeholders imvolvement

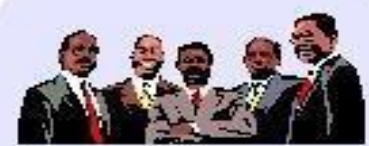

Occurs in various stages of ElA to ensure

- Quality, comprehensive and effectiveness

- That stakeholders views are adequately addressed

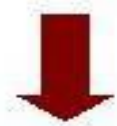

\section{EIA Report and Review}

ElA Report

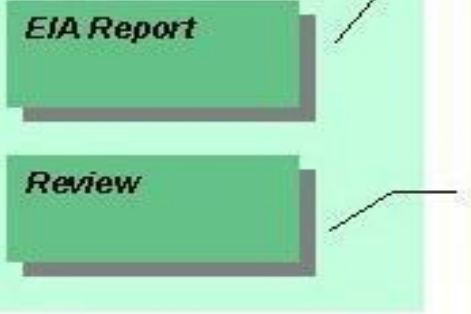

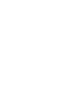

Impact Assessment and Mitigation Measures

Prediction of impacts

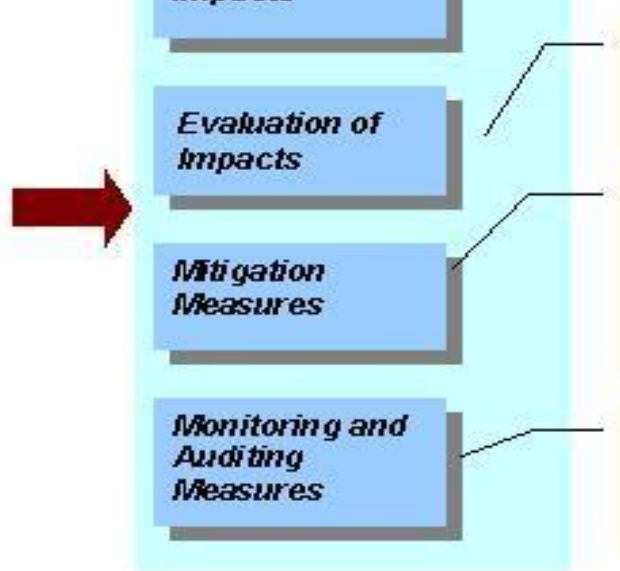

Compiled information in report format including

- Non-technical summary

- Methodologies used

- Results

- Interpretation

- Conclusions

- Assesses adequacy of issues addressed

- Facilitate the decision making process

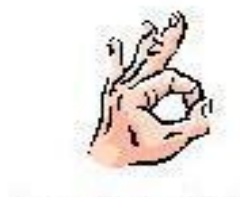

Keep the project

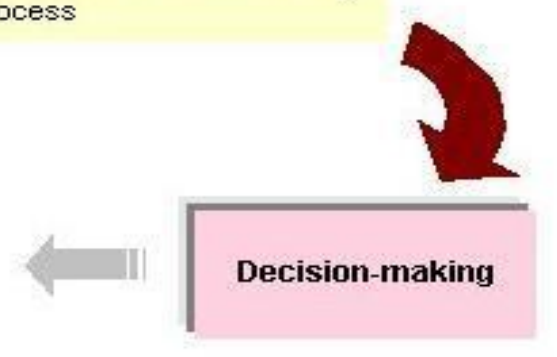

Quantit ative impact, such as

- Magnitude

- Extent

- Duration

Determine the impact

- Significance

- Importance

- To design systems andior processes to avoid, reduce and minimize adverse impacts

- To enhance beneficial outcomes

Identify impacts that require

- Monitoring

- Auditing

Summarize,

analyze, and

interpret

information

obtained

[Figure: EIA process and sequence of implementation [8]:] 
EIA [4], as a key instrument of the policy of EU and Bulgaria, should include:

1) Description of the investment proposal;

2) Determination of alternatives;

3) Description of environmental aspects on which the construction and exploitation of the investment proposals may have an impact;

4) Description of measures that can be taken to prevent or mitigate the adverse impacts;

5) Preparation of a Report, which should be discussed with the specialized agencies, stakeholders and public.

The indicators, used in the EIA [6], are divided into economic, social and environmental indicators and are specific for the different levels and sectors. In the EIA there are included more and more in-depth indicators than in other environmental assessments, in order to enable the implementation of more indepth assessment:

1) Indicators for evaluating the $\mathrm{EU}$ politics on sustainability at NUTS 2/NUTS 3 level - here the assessment is carried out by 66 indicators, which are divided into indicators reflecting the economic, the social and the environmental impacts. To assess the impact on the economic sphere, there are comprised of 20 indicators, divided into 8 groups. To assess the social impacts, there are selected 16 indicators, divided into 5 groups. The impact on the environment is carried out by 30 indicators divided into 8 groups.

2) Indicators for evaluating the EU politics on sustainability at LAU 1/LAU 2 level (former NUTS 4/NUTS 5) - At LAU 1/LAU 2 level there are included $\mathbf{5 6}$ indicators, which are more specific than those of the previous level. The main problem here is the lack or incorrectness of data. Official data (Eurostat, ESPON, national statistical institutes, etc.) are available for NUTS 3 level (the lowest one). There are partial data for LAU 1 level (population, acreage, employment, unemployment, etc.), but not for all indicators. The most serious lack of data is for the LAU 2 level. This is an important problem that needs a solution. The indicators are grouped similarly to those for NUTS 2/NUTS 3 level and here the number is as follows - $\mathbf{1 6}$ economic, $\mathbf{1 6}$ social and 24 indicators for environmental impact.

\section{CONCLUSIONS}

According to the World Economic Forum, the most serious environmental threats caused by man are pollution, mismanagement of land and water, overexploitation of species, unprecedented geophysical destruction and mismanaged urban sprawl. In order to achieve environmental sustainability, it is necessary to perform environmental assessments of all strategic and planning documents at different levels.

Environmental Impact Assessment (EIA) of investment proposals, as one of the main tools for preventive control, has a central role in developing investment proposals. It supports the process of achieving the goals of sustainable development, of reducing the adverse environmental impacts and of increasing its quality.

EIA is a legally established tool for preventive control in managing the environment by minimizing the adverse impacts of human activities.

Indicators, used in the EIA, are divided into economic, social and environmental indicators and are specific for the different levels and sectors. In the EIA there are included more and more in-depth indicators than in other environmental assessments, in order to enable the implementation of more in-depth assessment. The main problem here is the lack or incorrectness of data. The most serious lack of data is for the LAU 2 level. This is an important problem that needs a solution.

\section{REFERENCES}

1. http://www.tbmagazine.net/statia/protseduri -po-otsenka-na-vzdeistvieto-vrkhuokolnata-sreda

2. http://ecomedia.bg/business/ecobusiness/article/3278

3. http://www.ekomodel.eu/ocenka-navazdejstvieto-varxu-okolnata-sreda-ovos 
4. Doichinova $\mathrm{Yu}$, Ivan Kanchev, Albena Miteva, Zornitsa Stoyanova, Management aspects of eco-economic preparation of students at the University of National and World Economy, University Publishing "Economy", S., 2010

5. Directive $85 / 337 /$ EEC

6. Regulation on conditions and procedures of EIA (adopted 07. 03. 2003; last amend. 30. 11.2012).http://www3.moew.government.b g/files/file/Legislation/Naredbi/NAREDBA _za_usloviqta_i_reda_za_izvyrsvane_na_oc enka_na_vyzdejstvieto_vyrhu_okolnata_sre da_Zagl_izm_D.pdf

7. http://www.ekoekspert.com/ocenki-analiziekspertizi/ovos-ocenka-na-v-zdejstvieto-vrhu-okolnata-sreda

8. http://www.unescap.org/drpad/vc/orientatio $\mathrm{n} / \mathrm{m} 8 \_1 . \mathrm{htm}$

9. http://www.epa.ie/whatwedo/advice/eia/

10.http://www.eoearth.org/article/Environment al_Impact_Assessment\#gen2

11.http://www.fig.net/pub/fig_2002/Ts103/TS10_3_anago.pdf 